\title{
Estudo das Características Físicas e Hidráulicas de Concretos Permeáveis Com Rcd
}

Study of Physical and Hydraulic Characteristics of Permeable Concrete with Rcd

\section{Estudio de las Características Físicas e Hidráulicas del Hormigón Permeable con Rcd}

FERNANDES, Guilherme de Sousa ${ }^{1}$ MELO, Carlos Eduardo Luna de ${ }^{2}$

1Programa de Pós-Graduação - PPG-FAU, Universidade de Brasília, Brasília, Brasil. guilherme.sousa.fernandes@gmail.com ORCID: 0000-0001-5655-2814 2Programa de Pós-Graduação - PPG-FAU, Universidade de Brasília, Brasília, Brasil. carlosluna@unb.br ORCID: 0000-0003-2160-6776 


\title{
Resumo
}

A indústria da construção civil é importante para o crescimento econômico e social do país. Entretanto, o impacto ambiental causado é grande, tanto pelo consumo de recursos naturais como pela geração de resíduos. Com o crescente aumento das cidades está cada vez mais difícil ter um espaço para a correta destinação desses resíduos. Buscando uma maneira de mitigar tanto o problema da deposição dos resíduos como das inundações, esse trabalho propõe um concreto permeável produzido com resíduos da construção e demolição. Foram produzidos concretos porosos variando os teores de argamassa em $35 \%$ e $40 \%$ e os teores de substituição de agregados por RCD em $15 \%$ e $30 \%$. Foram feitos ensaios de resistência à compressão, índice de vazios, absorção, massa específica e permeabilidade. Os resultados dos ensaios mostraram que a redução da resistência pode ser de $23 \%$ quando da substituição de $15 \%$ do agregado natural por agregado reciclado, mas mesmo com essa redução é possível atingir as resistências ficaram maiores que $20 \mathrm{MPa}$. A substituição dos agregados resultou em ganhos de mais de $78 \%$ na permeabilidade.

Palavras-Chave: Concreto Poroso; Concreto Permeável; Resíduo da Construção e Demolição.

\begin{abstract}
The construction industry is important for the country's economic and social growth. However, the environmental impact caused is huge, because of the consumption of natural resources and the generation of waste. With cities growing more and more, it is increasingly difficult to have a space for the correct destination of this waste. Looking for a way to mitigate the problem of waste and flooding, this work proposes a pervious concrete with construction and demolition waste. Pervious concretes were produced varying the mortar contents by $35 \%$ and $40 \%$ and the substitution of aggregates for CDW by $15 \%$ and $30 \%$. Compressive strength, voids index, absorption, density and permeability tests were performed. The results of the tests showed that the resistance reduction can be $23 \%$ when replacing $15 \%$ of the natural aggregate with recycled aggregate, but even with this reduction it is possible to reach the resistances greater than $20 \mathrm{MPa}$. The replacement of the aggregates resulted in gains of $78 \%$ in permeability.
\end{abstract}

Key-Words: Porous Concrete; Permeable Concrete; Construction and Demolition Waste

\section{Resumen}

La industria de la construcción es importante para el crecimiento económico y social del país. Sin embargo, el impacto ambiental causado es grande, tanto por el consumo de recursos naturales como por la generación de residuos. Con el crecimiento de las ciudades, es cada vez más difícil tener un espacio para el destino correcto de estos residuos. En busca de una forma de mitigar tanto el problema de la deposición de residuos como las inundaciones, este trabajo propone un concreto permeable producido con residuos de construcción y demolición. Se produjeron hormigones porosos variando los contenidos de mortero en un 35\% y 40\% y los contenidos de sustitución de agregados por RCD en un $15 \%$ y $30 \%$. Se realizaron pruebas de resistencia a la compresión, índice de vacíos, absorción, densidad y permeabilidad. Los resultados de las pruebas mostraron que la reducción de la resistencia puede ser del $23 \%$ cuando se reemplaza el $15 \%$ del agregado natural con agregado reciclado, pero incluso con esta reducción es posible alcanzar resistencias superiores a $20 \mathrm{MPa}$. El reemplazo de agregados resultó en ganancias de más del $78 \%$ en permeabilidad.

Palabras Clave: Hormigón poroso; Hormigón permeable; Residuos de Construcción y Demolición. 


\section{Introdução}

A indústria da construção civil é de fundamental importância para o desenvolvimento econômico do país. Para que ela continue crescendo e operando à plena capacidade uma grande quantidade de recursos naturais deve ser utilizada. A maior parte desses recursos utilizados não são renováveis e caminham para seu esgotamento. Para se ter uma ordem de grandeza de como a indústria da construção civil consome recursos, Olivier et al (2016) cita que a indústria de cimento produziu 4 bilhões de toneladas em 2016 e que respondeu por 8\% das emissões de CO2 do planeta. Apesar dos esforços que a indústria da construção civil tem feito para adotar métodos construtivos mais racionais e reduzir desperdícios e consumo de recursos naturais, ela ainda é uma indústria altamente geradora de resíduos sólidos. Conquanto a mentalidade dos agentes do setor construtivo esteja se adaptando a nova mentalidade, mais racional, menos dispendiosa e mais sustentável, há aqueles que não se adaptaram e que não se preocupam com a geração e disposição desses resíduos gerados. Os impactos negativos ocasionados pela disposição incorreta e o não tratamento dos resíduos tem causado problemas a gestão urbana como: esgotamento prematuro de áreas de disposição, degradação do meio ambiente e prejuízo aos cofres públicos. Segundo ABRELPE (2019), em seu panorama dos resíduos sólidos de 2018 o total de resíduos de construção e demolição (RCD) recolhido no Brasil foi de aproximadamente 44,5 milhões de toneladas, sendo que desse número o DF foi responsável por cerca de 906 mil toneladas. Por RCD entende-se aqueles "provenientes de construções, reformas, reparos e demolições de obras de construção civil, e os resultantes da preparação e da escavação de terrenos" (BRASIL, Resolução CONAMA N ${ }^{\circ} 307$, de 5 de julho de 2002, 2002). Uma forma de balancear a extração de recursos naturais e geração de resíduos seria a utilização destes na própria indústria. Garantindo assim uma vida útil maior para os aterros e para as jazidas naturais, além de ressignificar RCD transformando-o em insumo e reduzindo os custos.

Os resíduos da construção já são reutilizados há algum tempo na fabricação de blocos de concreto, guias, como base na pavimentação e em concretos sem fins estruturais. Sabe-se que concretos com agregados reciclados possuem resistências e durabilidade menores que os concretos convencionais devido a sua maior porosidade. Partindo desses usos e da característica porosa desse material, essa pesquisa visa avaliar o efeito da incorporação de RCD em concretos porosos para uso como revestimentos permeáveis de concreto na pavimentação. Revestimentos permeáveis reduzem o volume de escoamento superficial, controlando a geração do mesmo na fonte e interceptando as águas pluviais. A figura 1 ilustra o processo de percolação de água pelos poros de um pavimento permeável em comparação com um pavimento impermeável.

Figura 1: Comparação do pavimento permeável com o pavimento impermeável

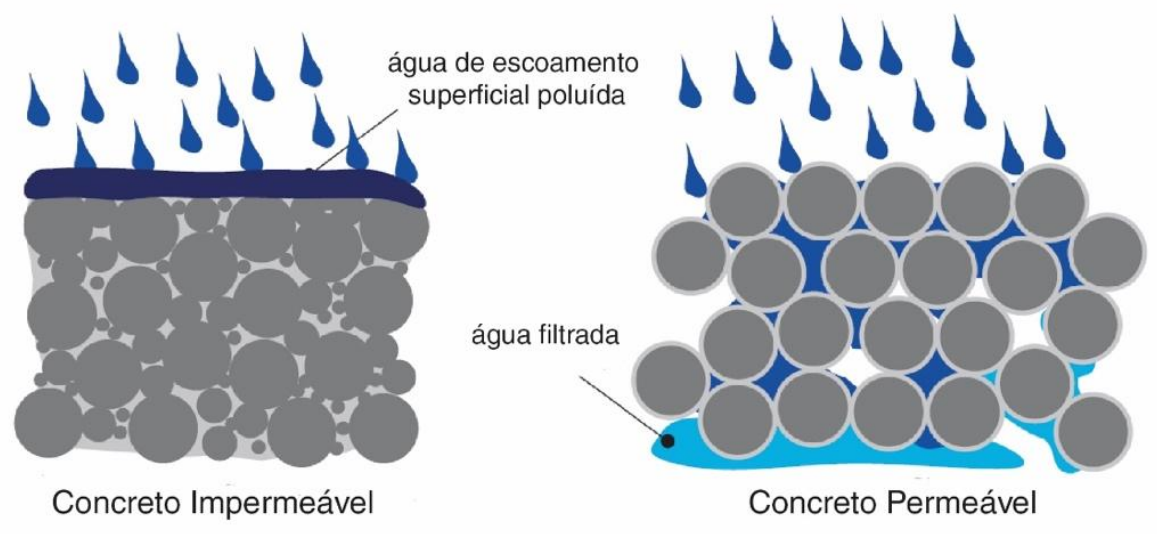

Fonte: Zhong et al (2018) 
Os benefícios proporcionados por esse tipo de revestimento são:

- Recarga dos lençóis freáticos em menos tempo pela infiltração da água da chuva mais rapidamente no solo;

- Filtragem da água do escoamento superficial fazendo com que a água que chegue no lençol freático ou seja lançada em corpos hídricos seja de melhor qualidade;

- O solo consegue se manter úmido devido a permeabilidade do revestimento o que aumenta o conforto térmico a nível do chão;

- Absorção dos ruídos dos veículos, além de evitar acúmulo de água nas pistas trazendo maior segurança aos motoristas;

- Os poros do concreto podem acumular calor, assim esses pavimentos podem ajustar a temperatura e umidade da região e mitigar as ilhas de calor.

As desvantagens desse tipo de revestimento são:

- Baixa resistência mecânica; e

- Necessidade de manutenção regular para evitar colmatação.

Ferguson (2005) contraindica esse tipo de pavimento em lugares com uma inclinação muito alta, grande fluxo de carros, onde o layout favoreça o acúmulo de material suscetível a colmatar ou que contenham poluentes que não possam entrar em contato com o solo. De forma a colaborar com a pesquisa acadêmica e a mitigação dos problemas de gestão de resíduos sólidos e de controle de enchentes, essa pesquisa estuda a utilização de RCD como material alternativo para a confecção de revestimentos permeáveis de concreto.

\section{Programa experimental}

Para essa pesquisa o programa experimental adotado consistiu em elaborar 6 traços variando teor de argamassa e substituição de agregados naturais por agregados de RCD, mas com mesma relação água/cimento $(0,35)$. Os traços se dividem em 2 grupos, um com teor de argamassa (d) de $35 \%$ e outro de $40 \%$. Cada grupo é composto de 3 traços, um de referência com $0 \%$ de substituição de agregado natural por agregado RCD, um traço com 15\% de substituição de agregado natural por agregado RCD e o último traço onde a substituição foi de $30 \%$. Esse limite de $30 \%$ foi estabelecido de acordo com que Hansen (1992) encontrou em seus estudos. A Tabela 1 traz a composição unitária dos traços utilizados nesse trabalho.

Tabela 1: Composição unitária dos traços

\begin{tabular}{lllllllll}
\hline Traço & C & AN & B 0 & B RCD & Adit. (g) & Água & $\boldsymbol{\alpha}(\%)$ & $\mathbf{H}(\%)$ \\
\hline 35/REF & 1,0 & 0,8 & 3,2 & - & & & & \\
35/15RCD & 1,0 & 0,8 & 2,8 & 0,5 & 5 & 0,35 & 35 & 7,0 \\
35/30RCD & 1,0 & 0,8 & 2,3 & 1,0 & & & & \\
\hline 40/REF & 1,0 & 1,0 & 3,0 & - & & & & \\
40/15RCD & 1,0 & 1,0 & 2,6 & 0,5 & 5 & 0,35 & 40 & 7,0 \\
40/30RCD & 1,0 & 1,0 & 2,1 & 0,9 & & & & \\
\hline
\end{tabular}

C: cimento; AN: areia natural; B0: brita 0; BRCD: brita rcd; adit: aditivo; a teor de argamassa; $\mathrm{H}$ : relação água/materiais secos 
Os agregados utilizados nessa pesquisa foram: pó de pedra, como agregado miúdo, brita 0 de origem calcária e brita 0 de RCD composta em maior parte por materiais cimentícios. Optou-se por agregados graúdos na faixa granulométrica de brita 0 , pois concretos permeáveis produzidos com esse tipo de agregado possuem resistências a compressão maiores. A Tabela 2 traz as características físicas dos agregados utilizados.

Tabela 2: Características físicas dos agregados utilizados

\begin{tabular}{llll}
\hline & $\begin{array}{c}\text { Pó de } \\
\text { Pedra }\end{array}$ & Brita 0 & $\begin{array}{l}\text { Brita 0 } \\
\text { RCD }\end{array}$ \\
\hline D máx (mm) & 4,8 & 12,5 & 9,5 \\
\hline Módulo de finura & 3,59 & 5,64 & 5,5 \\
\hline Massa específica $\left(\mathrm{g} / \mathrm{cm}^{3}\right)$ & 2,74 & 2,69 & 2,66 \\
\hline Massa unitária $\left(\mathrm{g} / \mathrm{cm}^{3}\right)$ & 1,16 & 1,08 & 1,42 \\
\hline Indíce de vazios $(\%)$ & 58,0 & 60,0 & 46,8 \\
\hline Material pulverulento (\%) & 4,4 & 1,6 & 0,9 \\
\hline Absorção (\%) & 1,5 & 1,2 & 5,8 \\
\hline \multicolumn{2}{c}{ Fonte: Autoral } \\
\end{tabular}

As principais diferenças entre a Brita 0 e a Brita RCD são o índice de vazios e a absorção. Como era esperado o agregado reciclado possui uma absorção muito maior que a do agregado natural, motivo esse que requer atenção na hora de concretar, pois isso significa que o agregado reciclado puxa mais água da mistura reduzindo $0 \mathrm{a} / \mathrm{c}$ efetivo. $O$ índice de vazios menor da brita 0 significa que esse agregado é muito mais compacto que o agregado natural.

A dosagem escolhida visa produzir um concreto com mais de $20 \mathrm{MPa}$. Para auxiliar nesse objetivo a escolha do cimento foi crucial. Para isso essa pesquisa trabalhou com um CP II-F-40, garantindo assim uma pasta de cimento com boa resistência para compensar os efeitos deletérios da maior porosidade do tipo de concreto a ser estudado. Além disso foi usado um aditivo poli funcional para ajudar na trabalhabilidade e redução de água do concreto.

\subsection{Preparo das amostras}

Foram moldados 12 corpos de prova cilíndricos nas dimensões de1 $0 \mathrm{~cm}$ de diâmetro e $20 \mathrm{~cm}$ de altura. Depois de moldados eles ficaram em cura em câmera úmida até a idade dos ensaios. As quantidades por ensaio e as idades de realização dos testes foram:

- 6 para compressão ( 3 aos 7 dias e 3 aos 28 dias);

- 3 para absorção de água e índice de vazios (28 dias);

- 3 para permeabilidade e compressão diametral (28 dias);

Um fator importante na moldagem dos corpos de prova é sua compactação. Para essa pesquisa compactou-se os corpos de em 3 camadas com 12 golpes de haste cada uma. A Figura 2 mostra os CP's após serem desmoldados. 
Figura 2: Corpos de prova após serem desmoldados

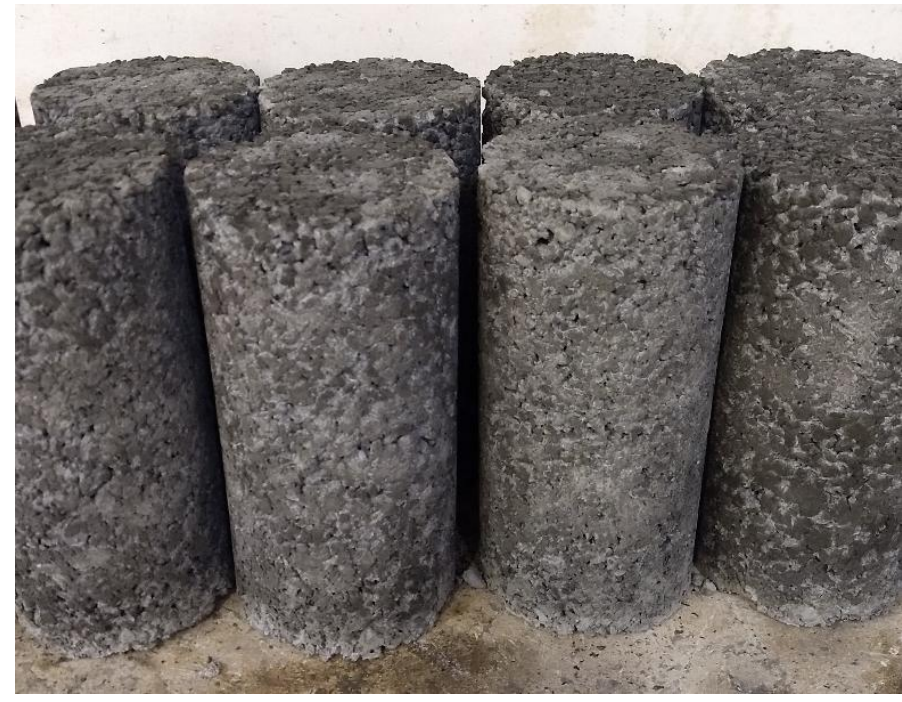

Fonte: Autoral

\subsection{Ensaios físico-mecânicos}

\subsubsection{Resistência à compressão}

Os corpos de prova foram ensaiados conforme o proposto pela ABNT NBR 5739:2007. Optou-se pelo capeamento com gesso (Figura 3), pois a retificação mecânica desagregava parte do topo dos corpos de prova.

Figura 3: Exemplo de capeamento dos corpos de prova com gesso

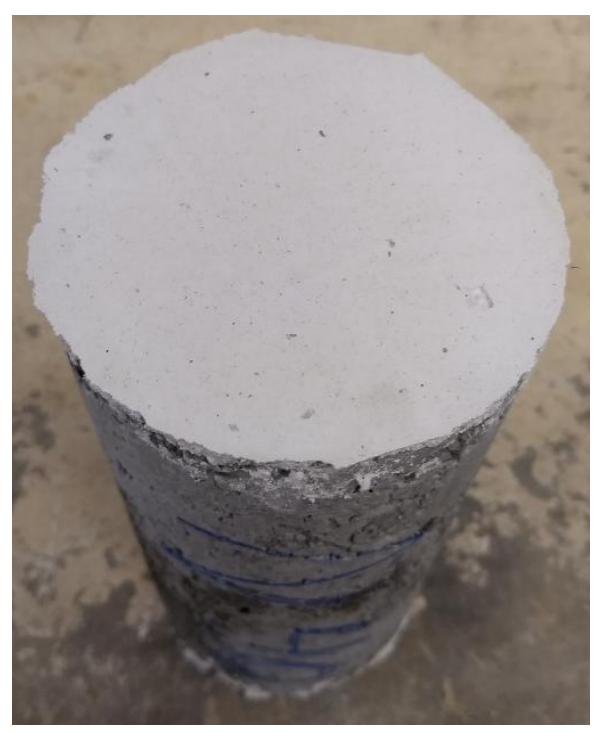

Fonte: Autoral

\subsection{2. Índice de vazios, absorção e massa específica}

O índice de vazios é o parâmetro que permite quantificar os poros permeáveis do concreto. Tanto o índice de vazios, absorção e massa específica são obtidos de acordo com a ABNT NBR 9778:2009.

\subsubsection{Permeabilidade}

O ensaio mais comumente utilizado para a determinação do coeficiente de permeabilidade e citado pela ACI 522R-10, é o teste de carga variável descrito por Neithalath et al (2003). O teste foi adaptado e o equipamento utilizado é mostrado na Figura 4. 
Figura 4: Equipamento para o ensaio de permeabilidade a carga variável

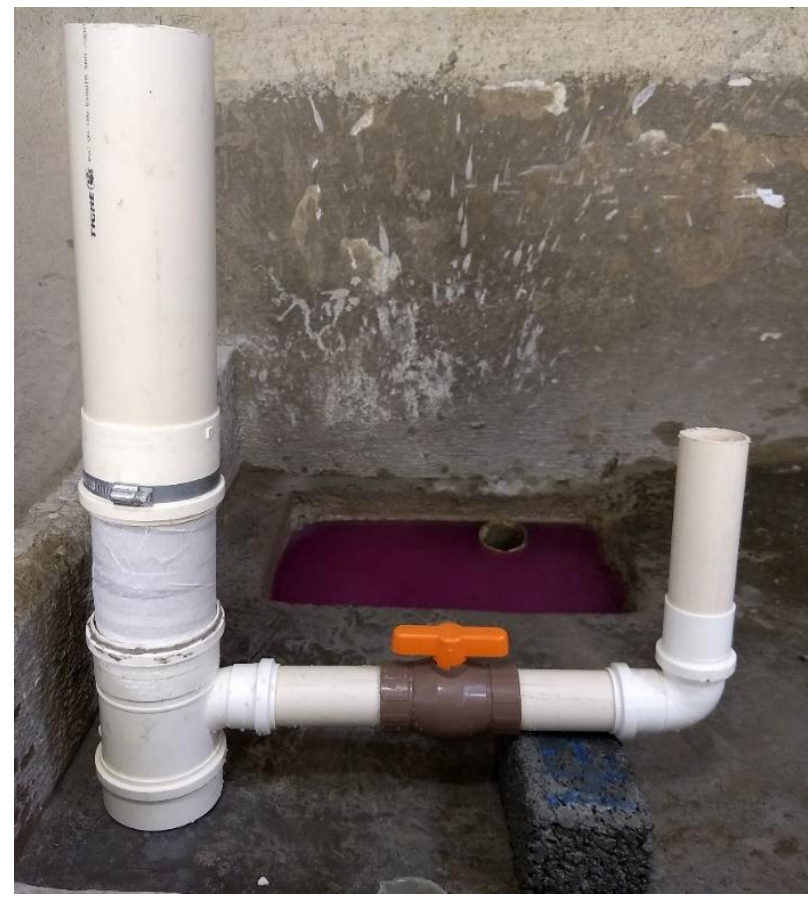

Fonte: Autora

O coeficiente de permeabilidade é determinado pela Lei de Darcy (Equação 1):

$K=\frac{A_{1} * l}{A_{2} * l} \log \left(\frac{h_{i}}{h_{f}}\right)$

Onde:

$\mathrm{K}=$ coeficiente de permeabilidade em $(\mathrm{mm} / \mathrm{s})$;

$\mathrm{A} 1$ = área da sessão da amostra em $\left(\mathrm{mm}^{2}\right)$;

$\mathrm{A} 2$ = área da sessão interna do tubo $\left(\mathrm{mm}^{2}\right)$;

$\mathrm{I}=$ comprimento da amostra $(\mathrm{mm})$;

$\mathrm{t}=$ tempo em (s)

hi = altura inicial da lâmina d'água em $(\mathrm{mm})$;

$\mathrm{hf}=$ altura da lâmina d'água em $(\mathrm{mm})$;

Para o ensaio dessa pesquisa, usou-se corpos de prova de $200 \mathrm{~mm}$ de altura. O ensaio consiste em medir o tempo que a água levou de uma altura inicial (hi) até uma altura final (hf), medidas a partir do topo do CP. Para esse ensaio seguiu-se Neithalath et al (2003) e hi $=290 \mathrm{~mm}$ e hf $=70 \mathrm{~mm}$. Os autores recomendam 3 leituras de tempo e que nessa pesquisa foram feitas em 3 CP's distintos. 


\section{Resultados}

\subsection{Resistência à compressão}

Os resultados de 7 e 28 dias de resistência à compressão, em MPa, para todos os traços são mostrados na Tabela 3 que traz os resultados dos 3 CP's ensaiados, a média, o desvio padrão, o coeficiente de variação, a variação de resistência de 7 para 28 dias e a variação de resistência dos concretos com agregado reciclado para o de referência. Quando o desvio padrão foi acima de 2, o valor mais discrepante da amostra foi descartado.

Tabela 3: Resistência à compressão em MPa dos corpos de prova cilíndricos para as idades de 7 e 28 dias

\begin{tabular}{|c|c|c|c|c|c|c|c|c|c|c|c|c|c|c|}
\hline \multirow{2}{*}{ TRAÇO } & \multicolumn{6}{|c|}{7 DIAS } & \multicolumn{6}{|c|}{28 DIAS } & \multirow{2}{*}{$\Delta 7 / 28$} & \multirow{2}{*}{$\Delta$ ref } \\
\hline & 1 & 2 & 3 & Med. & D.P. & C.V. & 1 & 2 & 3 & Med. & D.P. & C.V. & & \\
\hline REF35 & 26,6 & 26,8 & 26,7 & 26,7 & 0,1 & $0,3 \%$ & 29,1 & 26,6 & 36,8 & 27,8 & 1,3 & $4,6 \%$ & $4,4 \%$ & - \\
\hline 35/15RCD & 21,6 & 19,9 & 19,4 & 20,3 & 0,9 & $4,6 \%$ & 24,0 & 21,4 & 19,3 & 21,5 & 1,9 & $8,9 \%$ & $6,0 \%$ & $-22,7 \%$ \\
\hline 35/30RCD & 18,6 & 15,8 & 16,9 & 17,1 & 1,2 & $6,9 \%$ & 22,1 & 25,2 & 20,3 & 21,2 & 0,9 & $4,2 \%$ & $23,8 \%$ & $-23,9 \%$ \\
\hline REF40 & 30,0 & 31,4 & 27,6 & 29,7 & 1,6 & $5,2 \%$ & 23,5 & 41,7 & 27,2 & 25,3 & 1,9 & $7,3 \%$ & $-14,7 \%$ & - \\
\hline 40/15RCD & 15,2 & 14,6 & 14,1 & 14,6 & 0,5 & $3,1 \%$ & 28,5 & 23,6 & 18,9 & 26,1 & 2,4 & $11,2 \%$ & $45,6 \%$ & $-16,0 \%$ \\
\hline 40/30RCD & 16,2 & 16,9 & 16,7 & 16,6 & 0,3 & $1,7 \%$ & 21,1 & 22,6 & 13,7 & 21,9 & 0,8 & $3,4 \%$ & $31,5 \%$ & $-13,6 \%$ \\
\hline
\end{tabular}

Med. = média; D.P. = desvio padrão; C.V. = coeficiente de variação

Fonte: Autoral

Um dos traços teve resistência aos 7 dias maiores que aos 28 dias. Isso pode ter sido influência do capeamento, da cura, do excesso de compactação, do acúmulo desproporcional de pasta de cimento, ou de todos esses fatores juntos.

Percebe-se que com a substituição de agregado natural por agregado reciclado há um ganho de resistência maior de 7 para 28 dias. Isso pode ocorrer devido a presença de material pozolânico no agregado reciclado utilizado que é em sua maior parte cimentício e proveniente de uma região onde tipo de cimento mais comum é o CP II-Z-32.

A resistência à compressão de concretos porosos fica entre 7 e $25 \mathrm{MPa}$ (ZHONG e WILLIE, 2016). Com isso pode-se dizer que os concretos obtidos nessa pesquisa estão com resistências dentro do esperado e acima da média.

Para o teor de argamassa de 35\% a resistência à compressão diminuiu inversamente proporcional a substituição de agregados naturais por reciclados e a redução de resistência chegou a 23,9\% quando houve uma substituição de $30 \%$.

Para o teor de argamassa de $40 \%$ houve um acréscimo de $3 \%$ na resistência quando se substituiu $15 \%$ dos agregados naturais por reciclados e depois um decréscimo de $14 \%$ quando se substituiu $30 \%$ dos agregados.

Na sequência a Figura 5 traz um gráfico relacionando o teor de argamassa com a resistência à compressão para cada substituição de agregado (0\%, 15\% e 30\%). 
Figura 5: Resistência à compressão x teor de argamassa

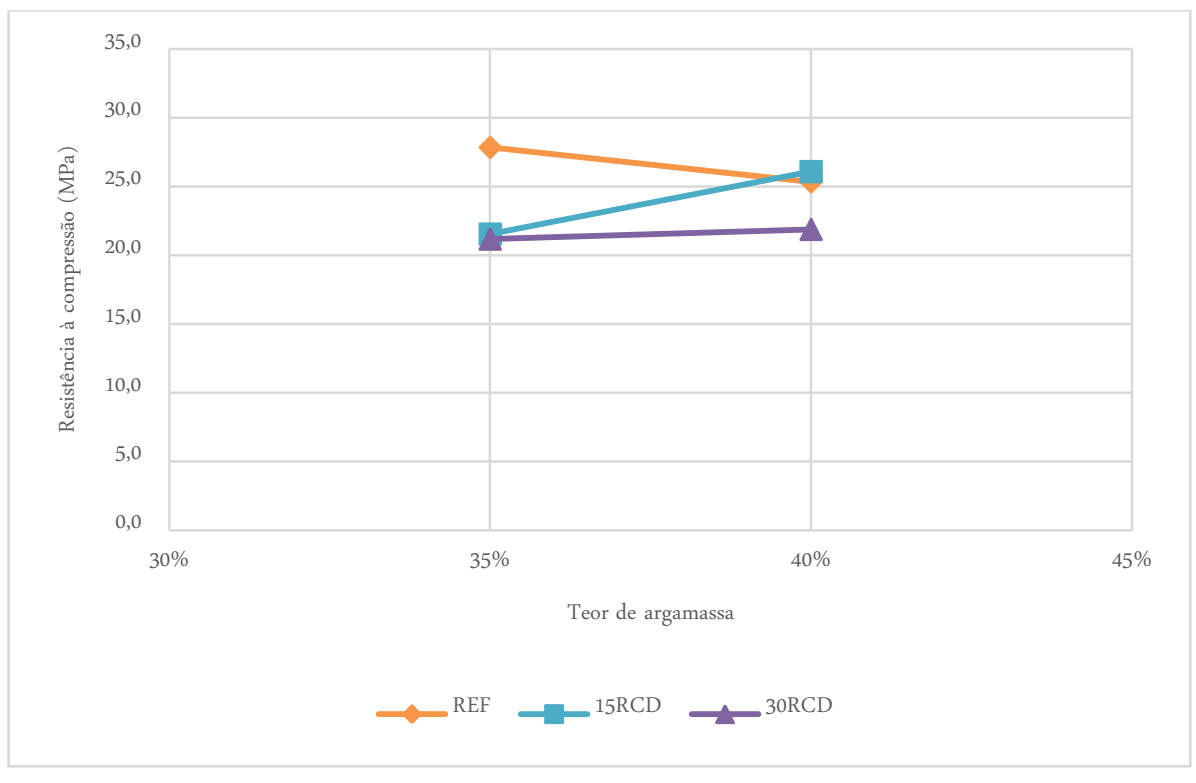

Fonte: Autoral

Na Figura 5 percebe-se que para a substituição de $30 \%$ de agregado natural por agregado de RCD não há diferença significativa (3\%) na resistência à compressão entre os teores de argamassa de $35 \%$ e 40\%. A inclinação da reta referente a 15RCD é a mais acentuada, o que mostra que nesse caso significa que um aumento ou diminuição do teor de argamassa tem o maior impacto na resistência dos 3 grupos. $E$ caso essas duas tendências se mantenham para teores de argamassa menores que 35\% seria melhor do ponto de vista da resistência à compressão trabalhar com concretos com $30 \%$ de agregado reciclado do que com $15 \%$.

A Figura 6 traz o gráfico da resistência à compressão em função da substituição de agregados naturais por reciclado para cada teor de argamassa (35\% e 40\%).

Figura 6: Resistência à compressão x substituição por RCD

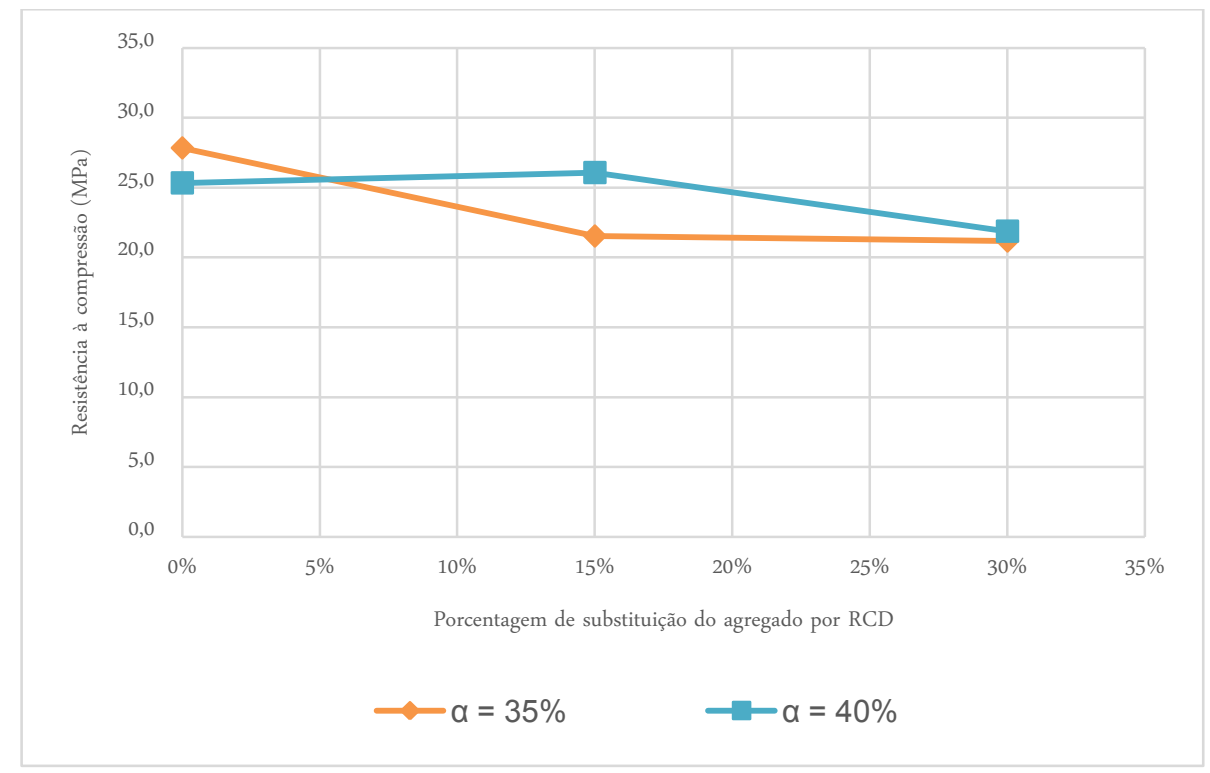

Fonte: Autoral

A Figura 6 mostra que para o teor de argamassa de $40 \%$ substituições de agregados naturais por de RCD entre $15 \%$ e $30 \%$ tem um impacto maior na resistência do que no teor de argamassa de $35 \%$ no 
mesmo intervalo de substituição.

\section{2. Índice de vazios, absorção e massa específica}

Os resultados dos ensaios de índice de vazios, absorção e massa específica estão na Tabela 4 abaixo.

Tabela 4: Resultados dos ensaios de índice de vazios, absorção e massa específica de todos os traços

\begin{tabular}{lllll}
\hline & $\begin{array}{l}\text { Massa } \\
\text { Específica Seca } \\
\left(\mathbf{g} / \mathbf{c m}^{3}\right)\end{array}$ & $\begin{array}{l}\text { Massa } \\
\text { Específica } \\
\text { Real }\left(\mathbf{g} / \mathbf{c m}^{3}\right)\end{array}$ & Absorção & $\begin{array}{l}\text { Índice de } \\
\text { vazios }\end{array}$ \\
\hline REF35 & 2,27 & 2,58 & $5,2 \%$ & $11,9 \%$ \\
$35 / 15 R C D$ & 2,19 & 2,56 & $6,6 \%$ & $14,4 \%$ \\
35/30RCD & 2,16 & 2,51 & $6,5 \%$ & $14,1 \%$ \\
\hline REF40 & 2,29 & 2,59 & $5,2 \%$ & $11,9 \%$ \\
40/15RCD & 2,21 & 2,53 & $5,8 \%$ & $12,8 \%$ \\
40/30RCD & 2,15 & 2,52 & $6,7 \%$ & $14,5 \%$ \\
\hline
\end{tabular}

Fonte: Autora

A redução da massa específica quando da substituição de agregado natural por agregado reciclado é explicada pelo fato do agregado de RCD ter uma massa específica menor. A substituição de $30 \%$ do agregado implicou numa redução da massa específica em $5 \%$ para o teor de argamassa de $35 \%$ e de $6 \%$ para o teor de $40 \%$.

O índice de vazios variou entre $11 \%$ e $15 \%$ e absorção de $5 \%$ a $7 \%$. Não houve uma tendência na absorção e no índice de vazios dos concretos de teor de argamassa $35 \%$. Entretanto, para o teor de argamassa de $40 \%$ quanto maior a quantidade de RCD no concreto, maior foi a absorção e o índice de vazios.

O gráfico do índice de vazios em função do teor de argamassa para todas as substituições de agregado está representado na Figura 7 e a Figura 8 traz o gráfico do índice de vazios em função da substituição dos agregados naturais por reciclados para os dois teores de argamassa.

Figura 7: Índice de vazios $\mathrm{X}$ teor de argamassa para todas as faixas de substituição de agregado

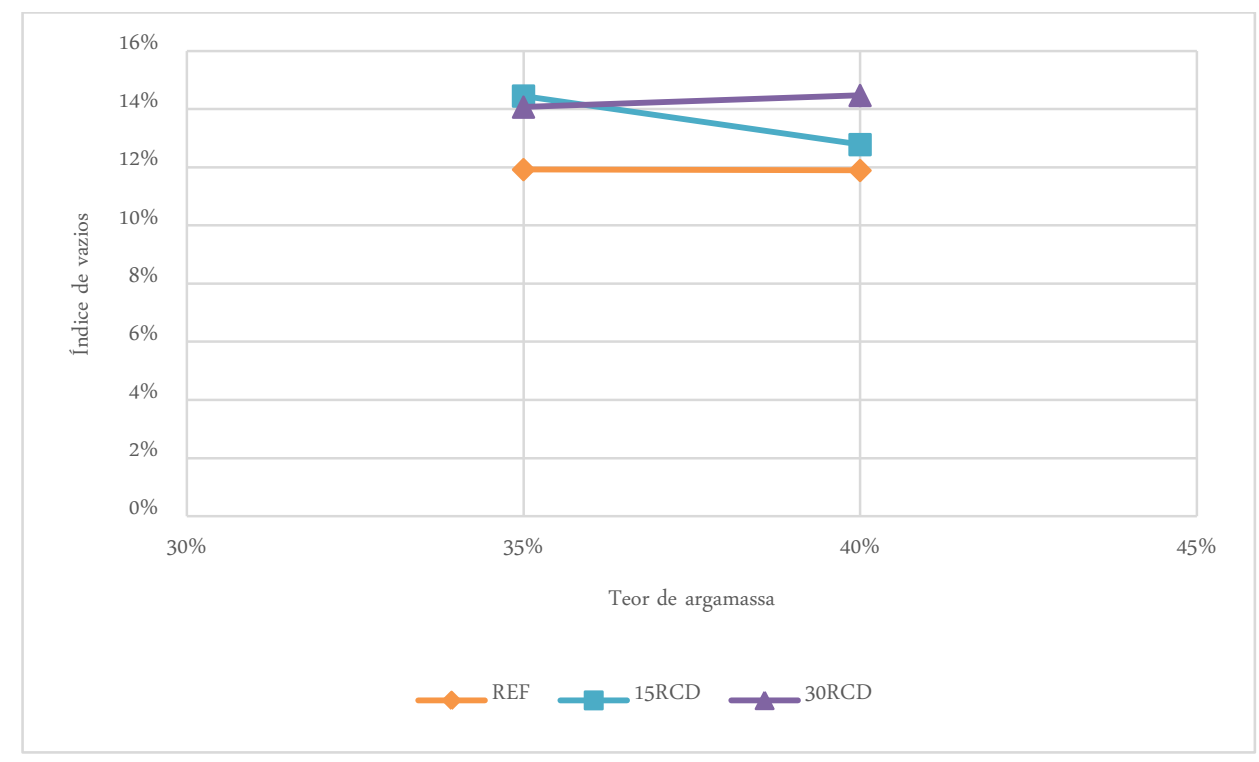

Fonte: Autoral 
Figura 8: Índice de vazios X porcentagem de substituição de agregado natural por RCD dos teores de argamassa $35 \%$ e $40 \%$

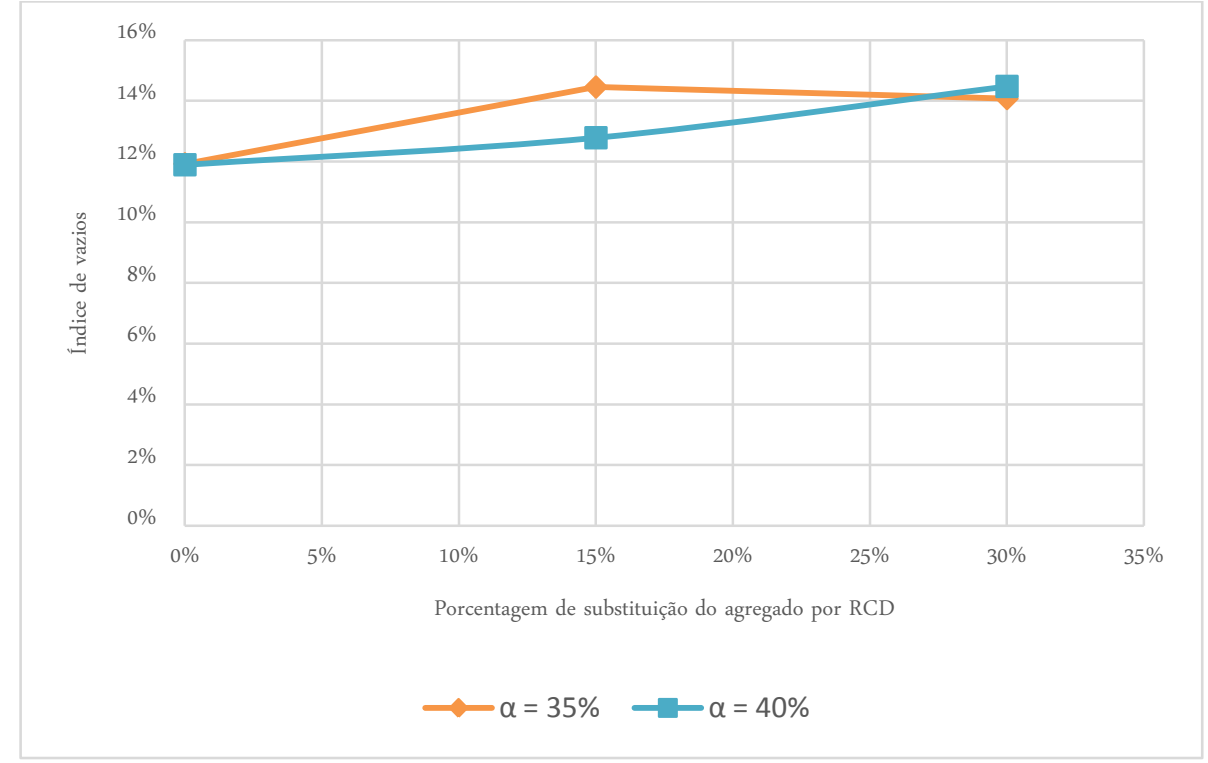

Fonte: Autoral

As duas figuras mostram que há uma proporcionalidade entre a substituição de agregado e o índice de vazios para o teor de argamassa de $40 \%$. Para o teor de $35 \%$ essa mesma proporcionalidade não foi identificada.

É possível observar a relação entre índice de vazios e resistência a compressão dos dois teores de argamassa na Figura 9.

Figura 9: Resistência à compressão X índice de vazios dos teores de argamassa 35\% e 40\%

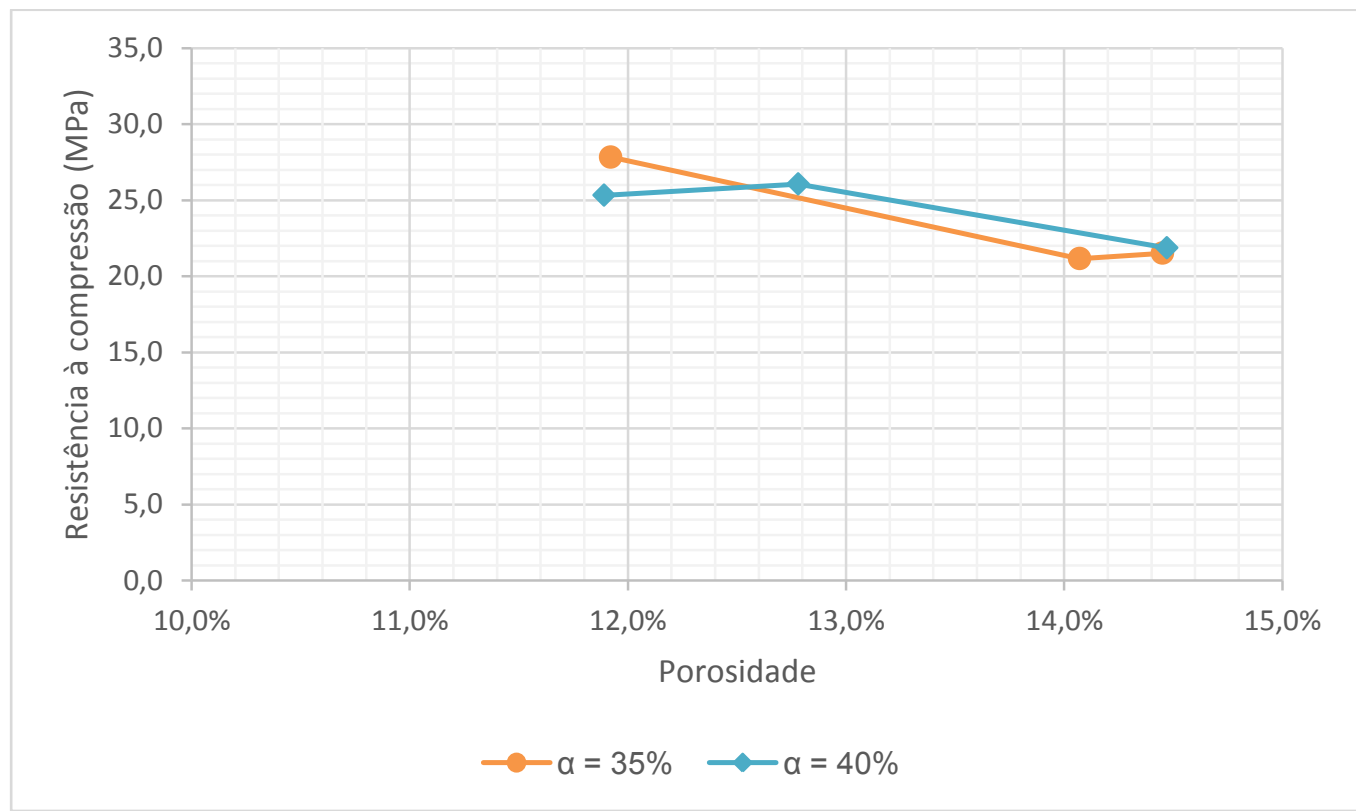

Fonte: Autora

A relação entre índice de vazios e resistência à compressão é primordial para os concretos porosos. A diferença entre o índice de vazios e a resistência à compressão dos traços 35/15RCD e 35/30RCD foi de $3 \%$ e 1,7\%, respectivamente, com isso, intui-se que o aumento de RCD na faixa estudada não afeta o traço no teor de argamassa de $35 \%$. 
Em contrapartida, para o teor de argamassa de $40 \%$ a substituição de $15 \%$ de agregados naturais por reciclado provocou um aumento no índice de vazios e um aumento na resistência à compressão.

\subsection{Permeabilidade}

A Figura 10 apresenta o gráfico da permeabilidade em função do teor de argamassa para todas as substituições de agregado. Enquanto a Fonte: Autoral

Figura 11 é o gráfico da permeabilidade em função da substituição dos agregados naturais por reciclados para os dois teores de argamassa.

Figura 10: Permeabilidade $\mathrm{X}$ teor de argamassa para todas as faixas de substituição de agregado

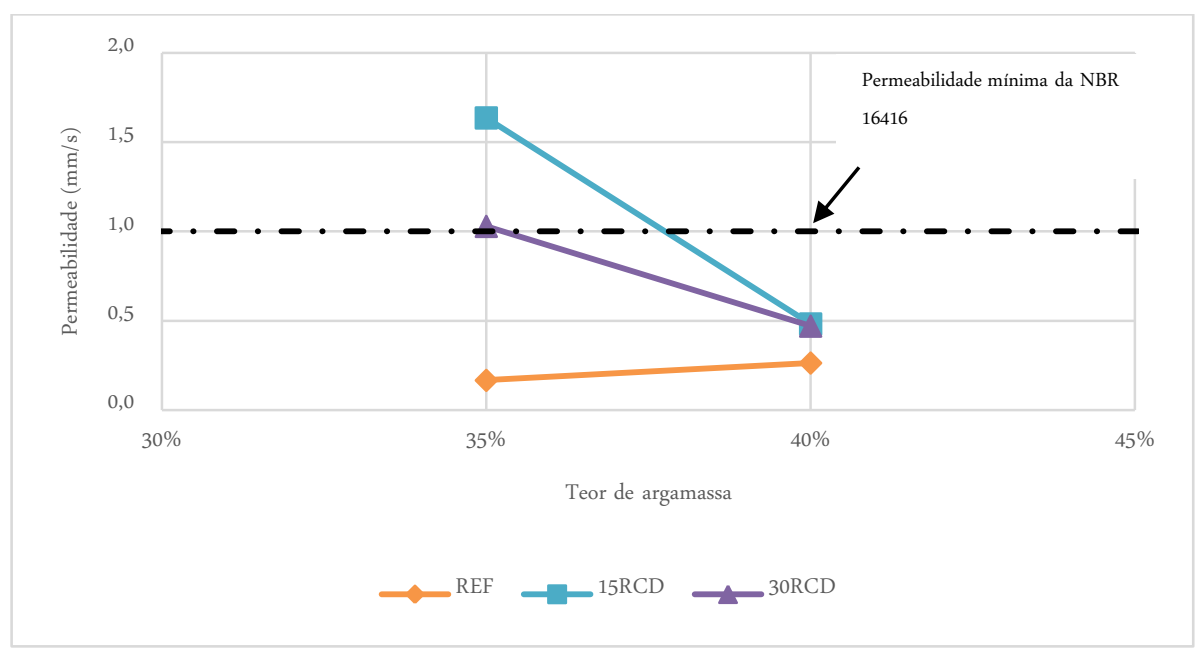

Fonte: Autoral

Figura 11: Permeabilidade $X$ porcentagem de substituição de agregado natural por RCD dos teores de argamassa $35 \%$ e $40 \%$

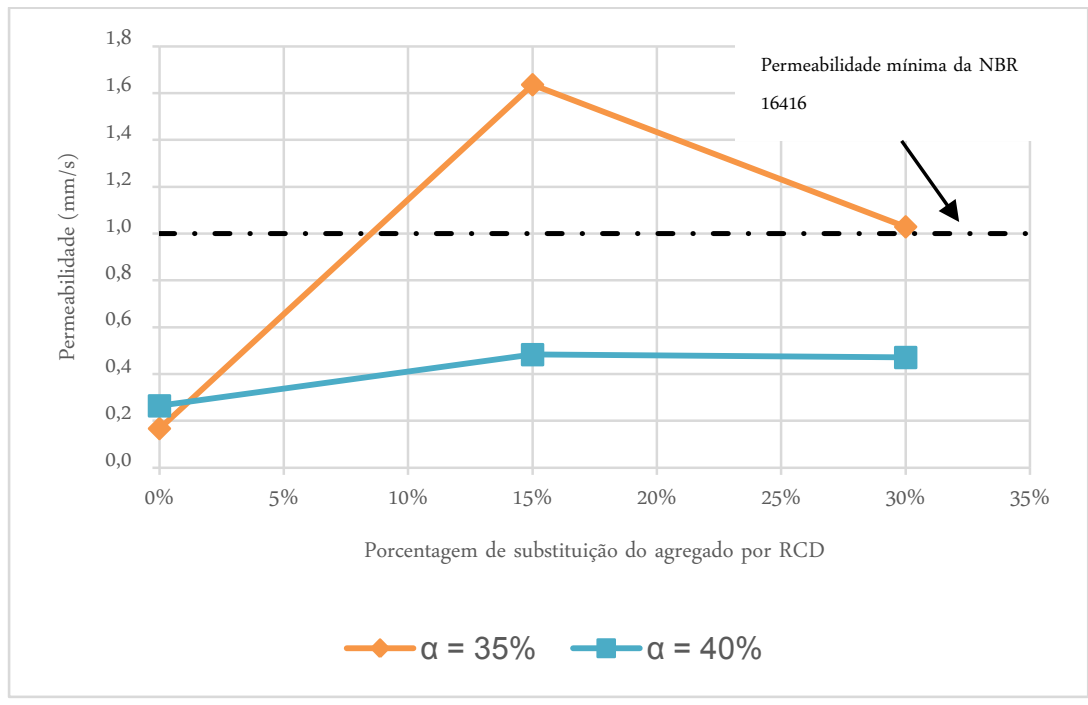

Fonte: Autora

De acordo com a ABNT NBR 16416:2015 a permeabilidade mínima que um concreto poroso deve ter é de $1 \mathrm{~mm} / \mathrm{s}$ e só atendem esse parâmetro os traços 35/15RCD e 35/30RCD.

Em ambas as figuras se percebe que o impacto da substituição por RCD é muito maior no teor de argamassa de $35 \%$, tendo um aumento de até $878 \%$ com relação ao de referência. Mesmo no teor de argamassa de $40 \%$ que esse aumento da permeabilidade foi menor, ele foi expressivo e chegou a $83 \%$. Esse aumento expressivo na permeabilidade pode acontecer devido aos poros internos dos 
agregados reciclados que aumentam a interconexão dos poros do concreto, assim a água tem mais caminhos por onde fluir.

Para os dois teores de argamassa a Figura 11 mostra que há um aumento da permeabilidade quando se substitui $15 \%$ dos agregados naturais por reciclados e depois um decréscimo com a substituição de mais $15 \%$. Enquanto para o teor de $40 \%$ essa diminuição é de $2,5 \%$, no teor de $35 \%$ chega a $37 \%$ de redução na permeabilidade.

\section{Conclusão}

A partir dos resultados encontrados nesse trabalho, conclui-se que a substituição de $15 \%$ dos agregados naturais por agregados reciclados reduz em $22 \%$ a resistência à compressão para o teor de argamassa de $35 \%$ e aumenta a resistência à compressão em 3\% para o teor de argamassa de 40\%. A substituição de $30 \%$ dos agregados naturais por reciclados resultou em uma redução de pelo menos $13 \%$ na resistência à compressão.

Não se percebeu proporcionalidade entre a porosidade e a resistência à compressão nos traços estudados. Mas se chegou a conclusão que o teor de argamassa de $35 \%$ é mais afetado pela substituição de agregados naturais por agregados reciclados e que a melhor substituição de agregados naturais por reciclados foi de $15 \%$.

Além disso, a substituição de RCD tem um efeito positivo maior na permeabilidade do que efeitos negativos na resistência à compressão.

\section{Agradecimentos}

Os autores agradecem a Coordenação de Aperfeiçoamento de Pessoal de Nível Superior (CAPES) agência de fomento do governo federal que providenciou auxílio financeiro para compra de equipamentos utilizados nessa pesquisa.

Os autores também agradecem ao Laboratório de Estudos em Materiais (LEM) da Universidade de Brasília (UnB) onde os ensaios foram desenvolvidos e a empresa Engemix/Votorantim Cimentos que providenciou os materiais para confecção do concreto.

\section{Referências}

ABNT - Associação Brasileira de Normas Técnicas. NBR 5739 - Concreto - Ensaios de compressão de corpos-de-prova cilíndricos. ABNT, Rio de Janeiro, 2018.

NBR 9778 - Argamassa e concreto endurecidos - Determinação da absorção de água, índice de vazios e massa específica. ABNT, Rio de Janeiro, 2009.

NBR 16416 - Pavimentos permeáveis de concreto - Requisitos e procedimentos. ABNT, Rio de Janeiro. 2015.

ABRELPE - Associação Brasileira de Empresas de Limpeza Pública e Resíduos Especiais. Panorama dos Resíduos Sólidos no Brasil 2018/2019. São Paulo, 2019

CONAMA - Conselho Nacional do Meio Ambiente. Resolução № 307, de 5 de julho de 2002. Conselho Nacional do Meio Ambiente, Ministério das Cidades, Secretária Nacional da Habitação. Publicada no Diário Oficial da União em 17/07/02.

FERGUSON, B. K. Porous Pavements. Florida, Estados Unidos: CRC Press, 2005. 577p.

HANSEN, T. C. Recycling of demolished concrete and masonry. London: Chapman \& Hall, 1992, 316p. Part one: Recycled aggregates and recycled aggregate concrete, p. 1-160. (RILEM TC Report 6). 
NEITHALATH, N; WEISS, W.J.; OLEK, J. Development of quiet and durable porous portland cement concrete paving materials. Final report, The Institute for Safe, Quiet and Durable Highways, p.179, 2003.

OLIVIER, Jos G. J.; JANSSENS-MAENHOUT, Greet; MUNTEAN, Marilena; PETERS, Jeroen A. H. W. Trends in global CO2 emissions: 2016 Report. PBL Netherlands Environmental Assessment Agency, Haia, 2016.

ZHONG, Rui; LENG, Zhen; POON, Chi-sun. Research and application of pervious concrete as a sustainable pavement material: A state-of-the-art and state-of-the practice review. Construction and Buildings Materials, v. 183, p. 544-553, 2018.

ZHONG, Rui; WILLE, Kay. Compression response of normal and high strength pervious concrete. Construction and Buildings Materials, v. 109, p. 177-187, 2016. 